\title{
Stability of Fluorosurfactant Adsorption on Mineral Surface for Water Removal in Tight Gas Reservoirs
}

\author{
Lijun You, ${ }^{1}$ Wanchun Zhang, ${ }^{1}$ Yili Kang, ${ }^{1}$ Zhangxin Chen, ${ }^{2}$ and Xuefen Liu ${ }^{1}$ \\ ${ }^{1}$ State Key Laboratory of Oil and Gas Reservoir Geology and Exploitation, Southwest Petroleum University, Chengdu 610500, China \\ ${ }^{2}$ Department of Chemical \& Petroleum Engineering, Schulich School of Engineering, University of Calgary, \\ Calgary, $A B$, Canada T2N 1 N4
}

Correspondence should be addressed to Lijun You; youlj0379@126.com

Received 10 October 2014; Revised 18 January 2015; Accepted 24 February 2015

Academic Editor: Sachin Jangam

Copyright (C) 2015 Lijun You et al. This is an open access article distributed under the Creative Commons Attribution License, which permits unrestricted use, distribution, and reproduction in any medium, provided the original work is properly cited.

\begin{abstract}
Long-term effectiveness of rock wettability alteration for water removal during gas production from tight reservoir depends on the surfactant adsorption on the pore surface of a reservoir. This paper selected typical cationic fluorosurfactant FW-134 as an example and took advantage of Fourier transform infrared spectroscopy (FTIR), X-ray photoelectron spectroscopy (XPS), and atomic force microscope (AFM) to investigate its adsorption stability on the rock mineral surface under the oscillation condition at high temperature for a long time. The experimental results indicate that the F element content on the sample surface increases obviously, the surface structure of fluorine-carbonization also undergoes a significant change, and the fluorine surfactant exhibits a good interfacial modification and wettability alteration ability due to its adsorption on the pore surface transforming the chemical structure of the original surface. The adsorption increases indistinctly with the concentration of over $0.05 \%$ due to a single layer adsorption structure and is mainly electrostatic adsorption because the chemical bonding between the fluorosurfactant and the rock mineral surface, the hydrogen bonding, is weak and inconspicuous.
\end{abstract}

\section{Introduction}

Tight gas reservoirs, one of main development objectives in the future dozens of years, are characterized by a high water phase trapping damage potential owing to the characteristic of water-wet and high capillary pressure. The water phase trapping damage can induce a fluid sensitivity damage, an aggravate stress sensitivity damage, and other damage [1], seriously affects an economic development of the tight gas reservoirs [2-4], and is difficult to be removed due to high capillary pressure of tight sandstone.

Surfactant interface modification is increasingly attracting more attention of reservoir engineers because it can reduce interface intension and alter wettability of rocks. Compared with ordinary hydrocarbon surfactant, fluorosurfactant possesses the outstanding characteristic of a high surface activity, high thermal stability, and high chemical stability [5], and its fluorine hydrocarbon exhibits a hydrophobic and oleophobic property. Owing to these properties, it has a very wide range of applications in the chemical, biological, mechanical, textile, papermaking, and oil industries. In the oil and gas industry, fluorine surfactant can be used as an oildisplacing agent, a wettability alternation agent, and a cleanup additive by improving the ability of fluid flow in porous media. Li and Firoozabadi [6] put forward the term "gaswetness." Their motive was to change rock wettability from water or oil wetness to gas-wetness for reduction or removal of liquid blocking or phase trapping damage. Since then, many papers presented research results about improving gas production by wettability alteration [7-15] and tested different surfactants at different reservoir temperatures. Li's group $[6-8,10,13]$ conducted experiments to change the wettability of tight sandstone with permeability of less than $0.1 \mathrm{mD}$ and they also reported a pilot field test in a tight gas-condensate reservoir to improve the gas production by wettability alteration. The production of the test well was increased to about $30,000 \mathrm{~m}^{3} /$ day, but the gas production declined very fast and it was only about $4,000 \mathrm{~m}^{3} /$ day after four days [16]. However, there have been few reports about the reason that the period of validity of improving gas production 
by wettability alteration was so short. Fluorine surfactant can modify the interface of a gas-water-rock system by adsorption on mineral surface to alter the wettability and surfactant adsorption behavior on the mineral surface and influences the long-term effect of wettability alteration. A key to maintaining the long-term effectiveness of wettability alteration is understanding the interaction of chemicals and rock $[17,18]$. Seiedi et al. [19] presented AFM images for quantitative assessment of the surface roughness for a wettability alteration investigation. Wu and Firoozabadi $[17,18]$ analyzed the long-term effectiveness of wettability alteration using core laboratory experiments.

In this study, we select a kind of fluorine surfactant FW134 which is able to successfully change water-wet tight sandstone into gas-wetness and improve the water flow rate by modifying the interface [12], and we select the mica to represent the main rock-forming minerals of tight sandstone. The purpose is to investigate the adsorption behavior and the ability of interface modification on the surface of rock mineral from microaspect under the conditions of simulated longterm water flow back from a high temperature gas reservoir.

\section{Materials and Methods}

2.1. Materials. Only a small part of clay minerals and carbonate cementation play an important role in surfactant adsorption, and their main components are layered silicate minerals, containing oxygen, silicon, aluminum, calcium, sodium, and potassium. Mica is easily split into pieces to obtain a smooth atomic hydrophilic surface [20], whose naked aluminum silicate lattice surface is similar to silica and many clay surfaces. In reality, we selected several rock-forming minerals like mica, kaolinite, and silica to conduct the adsorption, but this paper just selects fresh natural cleaved mica as a substrate to investigate fluorine surfactant adsorption on the high temperature solid-liquid interface. Fluorinated surfactant FW134 used is a kind of typical cationic fluorinated surfactant $\mathrm{C}_{8} \mathrm{~F}_{17} \mathrm{SO}_{2} \mathrm{NH}\left(\mathrm{CH}_{2}\right)_{3}\left(\mathrm{CH}_{3}\right)_{3} \mathrm{NI}$ containing a small amount of $\mathrm{N}, \mathrm{S}$, and $\mathrm{O}$ elements and its critical micelle concentration is $0.10 \%$. The surfactant is $99.9 \%$ pure. Distilled water is used to simulate the retention liquid like condensate water in the reservoir in order to avoid the effect of water salinity on the interaction of surfactants and rock mineral.

\subsection{Methods. Experimental procedures are as follows.}

(1) Wash with distilled water to remove impurities from the mica surface and put them into a constant temperature oven to dry to a constant weight at $60^{\circ} \mathrm{C}$.

(2) Crush the mica into powder, sieve the powder with $100 \sim 200$ meshes, and dry it to a constant weight at $60^{\circ} \mathrm{C}$.

(3) Make up $0.05 \%$ and $0.10 \%$ FW-134 solution with distilled water and FW-134 according to a 1:50 ratio of solid to liquid into the conical flask, respectively [21]. The 1:50 ratio of solid to liquid is from the results of a series of adsorption experiments of different solidliquid ratio to avoid the effect of the solid-liquid ratio on the surfactant adsorption.
(4) Shake up the mixtures, cover tightly the conical flasks with a plug, and immerse the flasks into the water bath oscillator to oscillate at $90^{\circ} \mathrm{C}$ for 40 hours. The purpose of oscillation is to simulate the reservoir detention water flow scouring to the pore surface during gas production. In order to ensure that the FW134 reaches saturation adsorption on solid surfaces, we test the adsorptive capacity $\Gamma$ changing with time on the mica surface. We can see from the results (Figure 1) that the adsorption equilibrium time is not more than 2 hours. We conduct the adsorption experiments for 40 hours, which is much more than the adsorption equilibrium time.

(5) Take out the conical flasks and leave them to rest for 30 minutes.

(6) Filter the precipitation separation of solid particles and soak up the residual solution on the solid particle surface with a filter paper.

(7) Dry solid particles to a constant weight at $60^{\circ} \mathrm{C}$, number them sample A (distilled water), sample B (0.05\% FW-134), and sample C $(0.10 \% \mathrm{FW}-134)$ according to the concentration of $\mathrm{FW}-134$ from low to high, and seal them for WQF-520 Fourier infrared (FTIR) spectrometer and Thermo Scientific Escalab $250 \mathrm{X}$-ray photoelectron spectroscopy (XPS) tests.

(8) Select fresh natural dissociated mica $(1 \mathrm{~cm} \times 1 \mathrm{~cm}$, thickness $<2 \mathrm{~mm}$ ) and immerse them into $0.1 \% \mathrm{FW}$ 134 solution according to a $1: 50$ ratio of solid to liquid at $90^{\circ} \mathrm{C}$ constant temperature water bath.

(9) Take out the mica plate after the oscillation for 40 hours, dry the surface with nitrogen flow to obtain the mica surface after the adsorption of FW-134, and fix the sample on a sample table of MMAFMLN 1728EX atomic force microscope (AFM) to test surface morphology. Nitrogen flow drying is to simulate gas flow scouring to the pore surface in the reservoir during gas production.

(10) Measure the surface contact angle.

\section{Experimental Results}

3.1. Characterization of Adsorption Behavior. Sample A, sample B, and sample C were analyzed by FTIR. These samples were obtained from mica powder immersed into distilled water, $0.05 \%$ and $0.10 \% \mathrm{FW}-134$ solution under $90^{\circ} \mathrm{C}$ for 40 hours' oscillation, as mentioned above. The FTIR results can be seen in Figure 1.

The peak at $3,625 \mathrm{~cm}^{-1}$ is the $\mathrm{O}-\mathrm{H}$ stretching vibration absorption peak of mica $\mathrm{Al}-\mathrm{OH}$ and $\mathrm{Mg}-\mathrm{OH}, 3,442 \mathrm{~cm}^{-1}$ the $\mathrm{O}-\mathrm{H}$ stretching vibration absorption peak of mica surface adsorbing water, and $630 \sim 1,640 \mathrm{~cm}^{-1}$ the $\mathrm{O}-\mathrm{H}$ bending vibration absorption peak; a high intensity peak at $1,024 \mathrm{~cm}^{-1}$ is the $\mathrm{Si}-\mathrm{O}$ absorption peak of stretching vibration, the absorption peak at $950 \sim 600 \mathrm{~cm}^{-1}$ is $\mathrm{O}-\mathrm{H}$ bending vibration, and a vibration zone at $800 \sim 500 \mathrm{~cm}^{-1}$ belongs to $\mathrm{Si}-\mathrm{O}-\mathrm{Al}$ spectral absorption peak. Using a comparative analysis of 


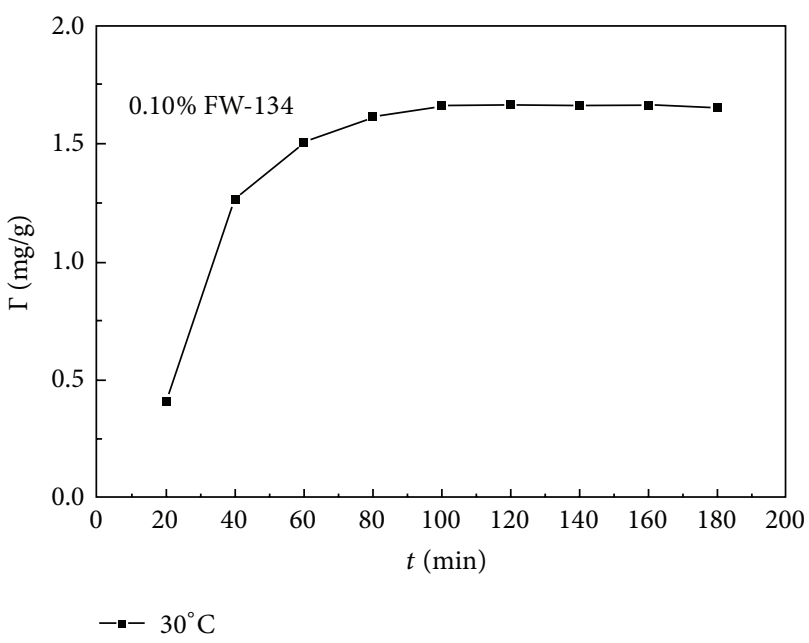

FIGURE 1: FW-134 adsorption capability on mica versus time.

the FTIR diagram, methyl $\mathrm{CH}_{3}$ and methylene $\mathrm{CH}_{2}$ stretching vibration absorption peaks appeared obvious at 3,000 $2,800 \mathrm{~cm}^{-1}$ in sample $B$ and sample $C$, and the absorption peak of stretching vibration of fluoroalkyl groups $\mathrm{CF}_{3}$ and $\mathrm{CF}_{2}$ also appeared at $1,350 \sim 1,120 \mathrm{~cm}^{-1}$. These indicate that FW-134 produces a significant adsorption on mica surfaces under the conditions of high temperature and long-term oscillations, but there is basically no obvious change of displacement, strength, or shape of the absorption peak from the whole FTIR graph characteristics before and after adsorption, suggesting that the chemical bond between FW134 and the mica surface is weak and the adsorption is mainly physical adsorption. The peaks $1800 \sim 1200 \mathrm{~cm}^{-1}$ in sample A and sample B are the same, which hardly appear in sample C. This shows that this peak is not related to the surfactant adsorption and will not affect the experiment results.

A mica surface has a strong capacity of bonding hydroxyl groups, polar atoms like $\mathrm{F}, \mathrm{N}$, and $\mathrm{O}$ are easy to form a hydrogen bond with the surface hydroxyl groups, and mica surfaces in aqueous solution are negatively charged, so FW134 , a kind of cationic fluorinated surfactant, is easy to be adsorbed on mica surfaces due to the electrostatic force, dispersion force, hydrogen bond, and other physical and chemical effects. However, it can be seen in Figure 2 that $\mathrm{O}-\mathrm{H}$ stretching vibration absorption displacement, strength, and shape of surface water on the samples with different concentration of FW-134 are the same, and the peak is at $3,442 \mathrm{~cm}^{-1}$, which shows that the bonding force between FW-134 molecules and the mica surface hydroxyl bond is weak. This may be due to the fact that hydrogen bonds are destroyed at high temperature, or the hydrogen bonding adsorption effect is weak, and it is not reflected in the FTIR diagram. These suggest that the main mechanism of FW-134 adsorption under the condition of high temperature is not a hydrogen bond.

3.2. Energy Spectrum Analysis of Surface Structure. We take an advantage of XPS to test the energy spectrum of sample

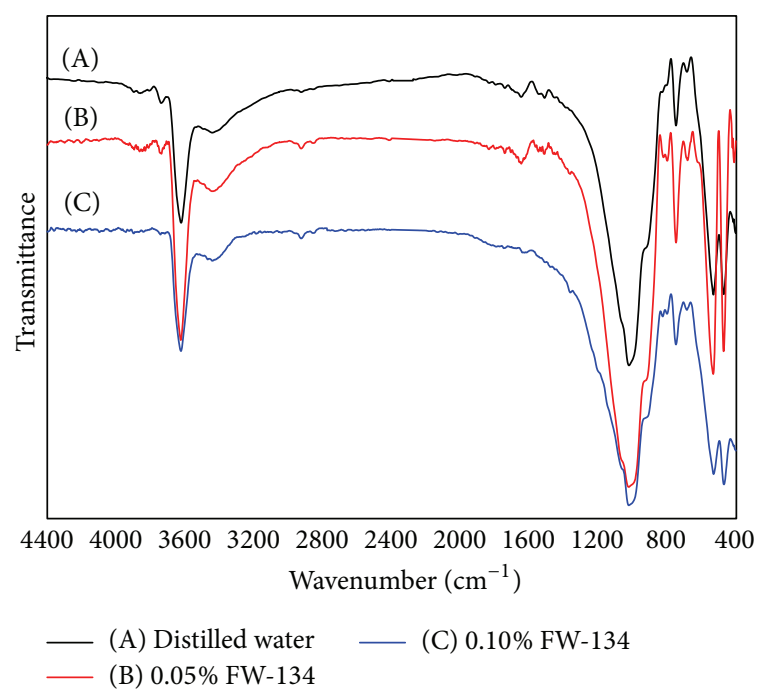

Figure 2: FT-IR spectra of samples adsorbing FW-134.

$A$, sample $B$, and sample $C$, and the results are seen in Figure 3. The XPS spectra curve analysis and fitting were conducted using the software XPS Peaks 4.1 developed by University of Hong Kong. We analyze the binding energy of Al2p, Si2p, C1s, K2p, O1s, F1s, N1s, and S2p of different samples. As shown in Figure 3, the binding energy of Al2p, Si2p, K2p, and O1s and the curve shape do not change with the concentration of FW-134; the binding energy of F1s, N1s, and S2p of sample B and sample C increases significantly compared with that of sample A and appears at $689 \mathrm{eV}, 402 \mathrm{eV}$, and $169 \mathrm{eV}$, respectively.

The content and the binding energy of each element are calculated according to the peak area (Tables 1 and 2).

Sample A, with no FW-134 adsorption on the mica, only contains trace $\mathrm{F}, \mathrm{N}$, and $\mathrm{S}$ element, while the $\mathrm{F}, \mathrm{N}$, and $\mathrm{S}$ element contents in sample B and sample $\mathrm{C}$ with the adsorption of FW-134 increase significantly, and the content of the $\mathrm{F}$ element increases from $0.598 \%$ to $17.545 \%$ and $22.037 \%$, the content of $\mathrm{N}$ element from $0.577 \%$ to $2.092 \%$ and $2.616 \%$, and the S content from $0.502 \%$ to $1.166 \%$ and $1.400 \%$ (Table 1), respectively. These showed that a large amount of FW-134 is adsorbed on the mica surface under the conditions of 40 hours' oscillations at $90^{\circ} \mathrm{C}$.

The element binding energy (B.E.) in these samples can be seen in Table 2. The binding energy of Al2p, Si2p, K2p, and O1s in samples B and C has little difference with that of sample A (Table 2), which shows that, under the conditions of high temperature, the chemical bonding force between FW134 and the mica surface is weak. This is also consistent with the result from the infrared spectrum analysis. In order to further determine the FW-134 adsorption pattern on the mica surface, F1s XPS peaks of each sample were analyzed by Gauss fitting spectra, as shown in Figure 4.

The Fls peaks of all samples are a single peak (Figure 4), so the chemical structure of their F element is relatively single. The pulse signal of the F1s peak of sample A is strong, and the peak intensity and peak area are small, which show that 
TABLE 1: XPS element content data of sample systems adsorbing FW-134.

\begin{tabular}{lcccccccc}
\hline Content (\%) & Al2p & Si2p & C1s & K2p & O1s & F1s & N1s & S2p \\
\hline Sample A & 13.245 & 17.383 & 11.470 & 4.950 & 51.768 & 0.598 & 0.577 & 0.502 \\
Sample B & 10.269 & 13.458 & 7.588 & 4.689 & 43.194 & 17.545 & 2.092 & 1.166 \\
Sample C & 9.3410 & 11.949 & 10.377 & 4.327 & 37.953 & 22.037 & 2.616 & 1.400 \\
\hline
\end{tabular}

TABLE 2: XPS $E_{B}$ data of sample systems adsorbing FW-134.

\begin{tabular}{lcccccccc}
\hline Binding energy $(\mathrm{eV})$ & Al2p & Si2p & C1s & K2p & O1s & F1s & N1s & S2p \\
\hline Sample A & 74.26 & 102.42 & 284.76 & 293.1 & 531.58 & 685.07 & 401.92 & 169.16 \\
Sample B & 74.62 & 102.80 & 286.55 & 292.97 & 531.66 & 689.19 & 402.77 & 169.23 \\
Sample C & 74.50 & 102.65 & 286.31 & 292.67 & 531.69 & 689.06 & 402.79 & 169.02 \\
\hline
\end{tabular}

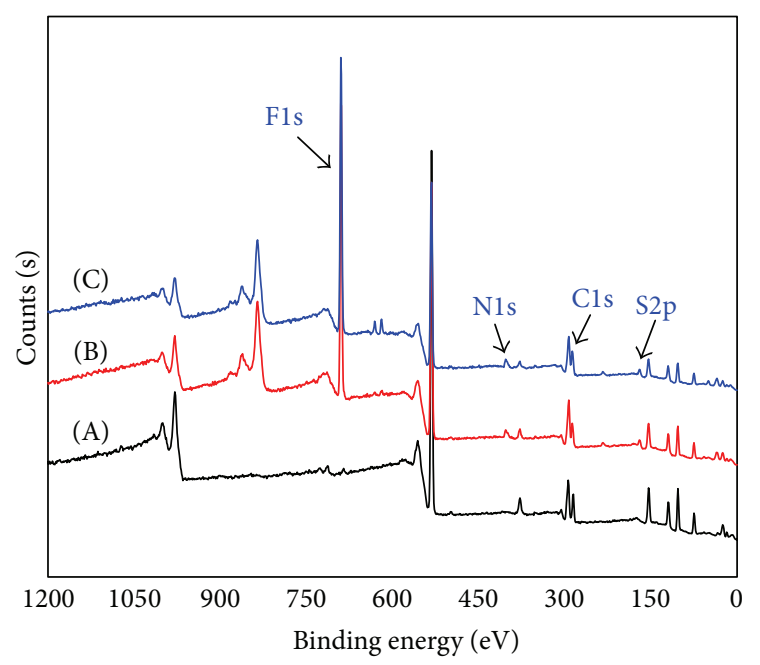

(A) Distilled water $\quad$ (C) $0.10 \%$ FW-134
(B) $0.05 \%$ FW-134

FIGURE 3: XPS spectra of sample systems adsorbing FW-134.

there is less F content in sample A (Figures 4(a) and 4(d)). The curves of samples B and C in Figures 4(b) and 4(c) are smooth and orderly, and the intensity and peak area of the F1s peak are large, which suggests that a lot of the $\mathrm{F}$ element is in the surface structure of samples B and C and a great deal of FW-134 adsorption is on the mica surface.

The Fls peak positions of samples B and C are different from those of sample A, and the Fls peak binding energy of sample B and sample C is basically the same (Figure 4(d) and Table 2). That is, the F1s peak position and chemical structure of $\mathrm{F}$ atom before and after adsorption on the surface are different. The F1s peak binding energy of sample A is $685.2 \mathrm{eV}$, the Ca-F structure of mica; the Fls peak binding energies of sample B and sample $\mathrm{C}$ are about $689.1 \mathrm{eV}$, the structure of chain C-F; there are no hydrogen bonding peaks in sample $\mathrm{B}$ and sample $\mathrm{C}$. These indicate that the chemical bonding strength between FW-134 and the mica surface is weak under the condition of high temperature, that covering is the main mechanism of different concentration of FW-134 adsorption on the surface of mica, and that physical adsorption rather than hydrogen bonding is the main mechanism of FW134 adsorption under the condition of the 40 hours' water oscillation.

The Gauss fitting spectra of the C1s XPS peaks of samples are shown in Figure 5. As shown in Figure 5(a), the Cls peak of sample A was split into four peaks; peak 1 and peak 2 are classified as a type of peak; the binding energies from low to high are for $\mathrm{C}-\mathrm{H} \backslash \mathrm{C}-\mathrm{C}, \mathrm{C}-\mathrm{O}$, and $\mathrm{C}=\mathrm{O}$ peaks. As shown in Figures 5(b) and 5(c), the Cls peaks of sample B and sample $\mathrm{C}$ were divided into three peaks, respectively. Their binding energies from low to high are for $\mathrm{C}-\mathrm{H} \backslash \mathrm{C}-\mathrm{C}, \mathrm{C}-\mathrm{N} \backslash \mathrm{C}-\mathrm{C}$, and C-F peaks.

The analysis results of the peak binding energy and peak area are shown in Table 3. The C-H $\backslash \mathrm{C}$-C peak area of sample A reaches $88.80 \%$, and a small piece of the $\mathrm{C}-\mathrm{O}$ and $\mathrm{C}=\mathrm{O}$ peak area appears in the Cls peak (Table 3). This may be caused by the chemical structure of carbon on the sample original surface or adsorption of $\mathrm{CO}_{2}$ in the air on the surface. Compared with sample $A$, sample $B$ and sample $C$ have a large area of the C-F and C-N $\backslash \mathrm{C}-\mathrm{C}$ peaks, whose total peak area is, respectively, $85.88 \%$ and $81.63 \%$, while the peak area of C$\mathrm{H} \backslash \mathrm{C}$-C is greatly reduced. The reason is that a large amount of FW-134 adsorbed covers on the mica surface to change the chemical structure of the original surface carbon under the high temperature water oscillation.

3.3. Evaluation of Surface Conformation and Modification Effect. The water adsorption on modified surface of minerals depends on the surface structure [22]. In order to observe the morphology to further understand the FW-134 adsorption structure and interfacial modification effect on the mica surface, a mica surface treated by a 40 hours' oscillation with $0.1 \% \mathrm{FW}-134$ solution and nitrogen flow drying under high temperature was tested by atomic force microscope (AFM). Figures 6 and 7 are the AFM scanning plane height map and three-dimensional map of the treated mica surface before and after cleaning of distilled water.

As intuitively seen in Figure 6, a lot of FW-134 molecules adsorbed on the mica surface are unequal granular and massive distribution phenomenon; the adsorption of FW134 covers up to $80 \%$ of the testing scope with $10 \mu \mathrm{m} \times$ $10 \mu \mathrm{m}$; the adsorption layer is thin. The contact angles of water on the adsorption surface treated by $0.05 \%, 0.1 \%$, and 
TABLE 3: XPS results of samples adsorbing FW-134 calculated by Gauss method.

\begin{tabular}{lccc}
\hline Sample & Type of structure & Binding energy $(\mathrm{eV})$ & Peak area $(\%)$ \\
\hline \multirow{2}{*}{ A } & C-H C-C & 285.0 & 88.80 \\
& C-O & 286.5 & 5.70 \\
\hline & C=O & 288.8 & 5.50 \\
B & C-H C-C & 285.0 & 14.22 \\
& C-N C-C & 285.7 & 46.07 \\
\hline & C-F & 286.8 & 39.81 \\
C & C-H C-C & 285.0 & 18.37 \\
& C-N C-C & 285.7 & 38.90 \\
& C-F & 286.8 & 42.73 \\
\hline
\end{tabular}

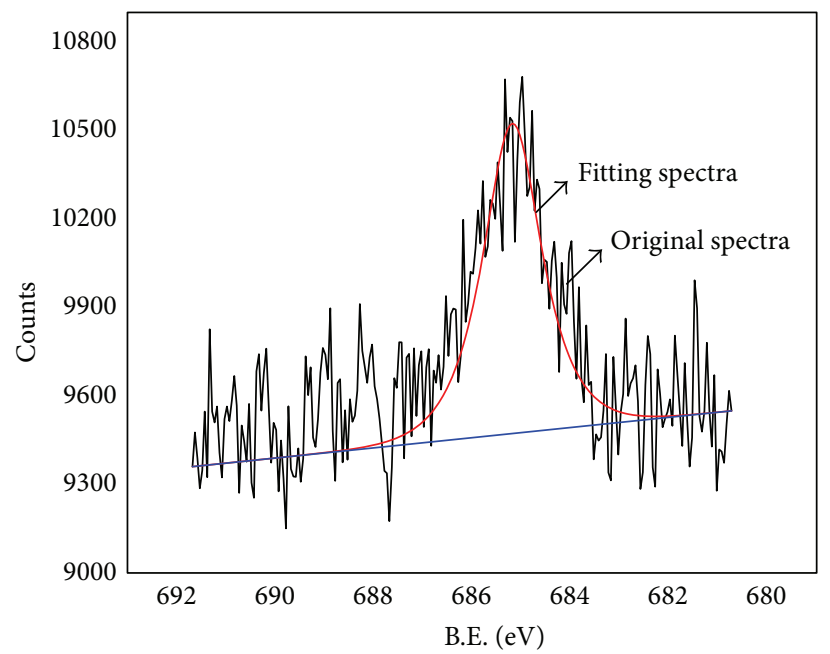

— Distilled water

(a)

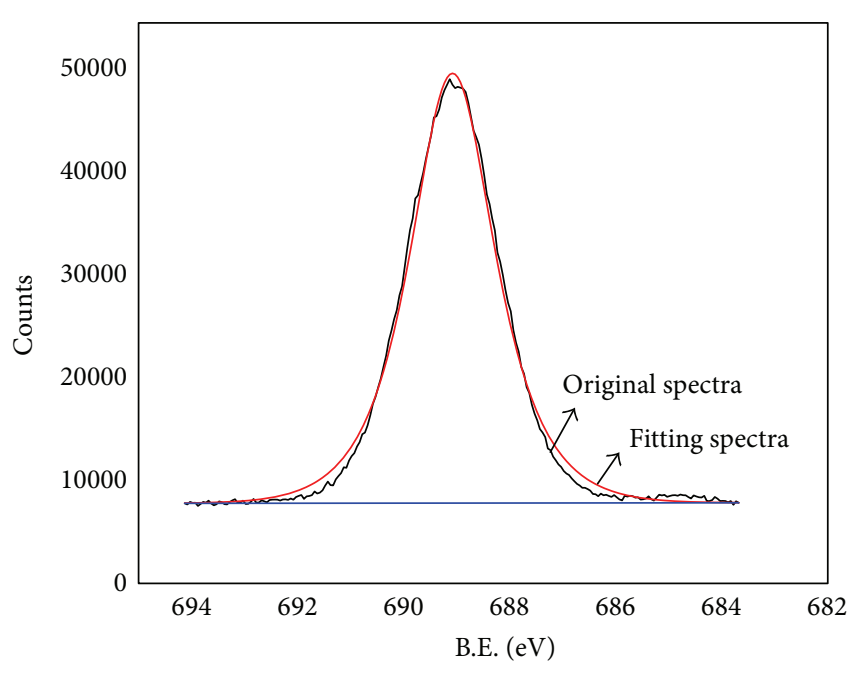

$0.10 \%$ FW-134

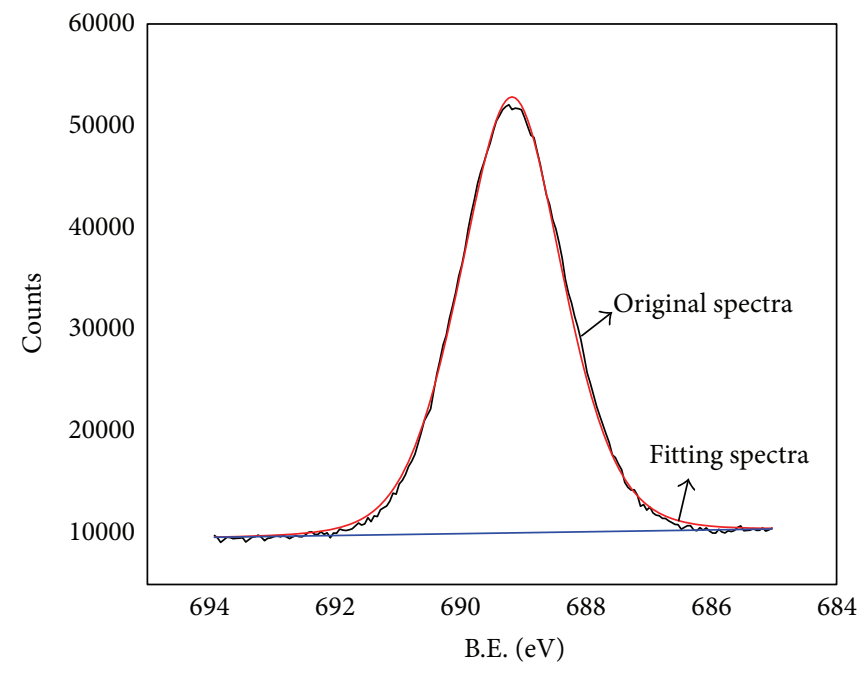

$0.05 \%$ FW- 134

(b)

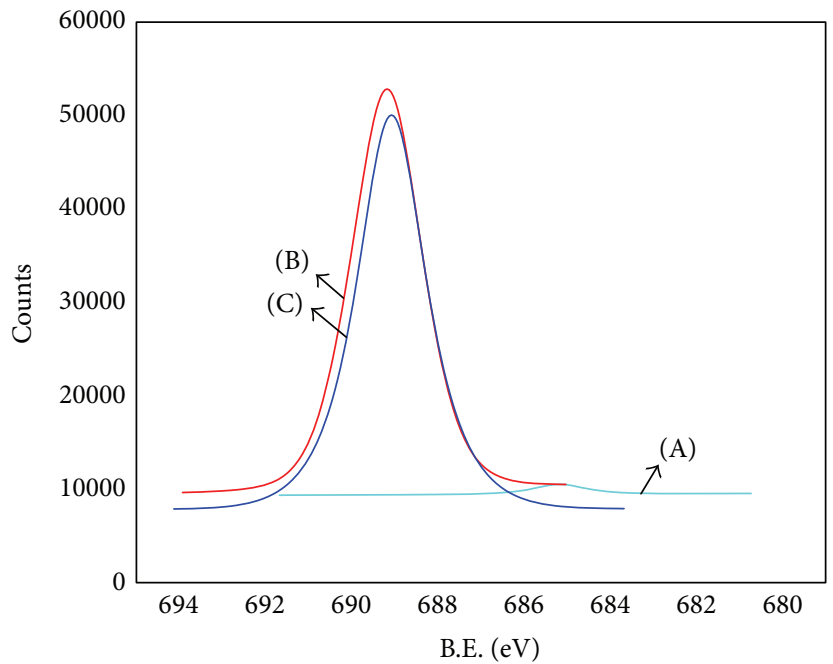

(A) Distilled water

(B) $0.05 \% \mathrm{FW}-134$

(d)

(c)

FIGURE 4: XPS C1s spectra of sample systems adsorbing FW-134 and contrast diagram. 


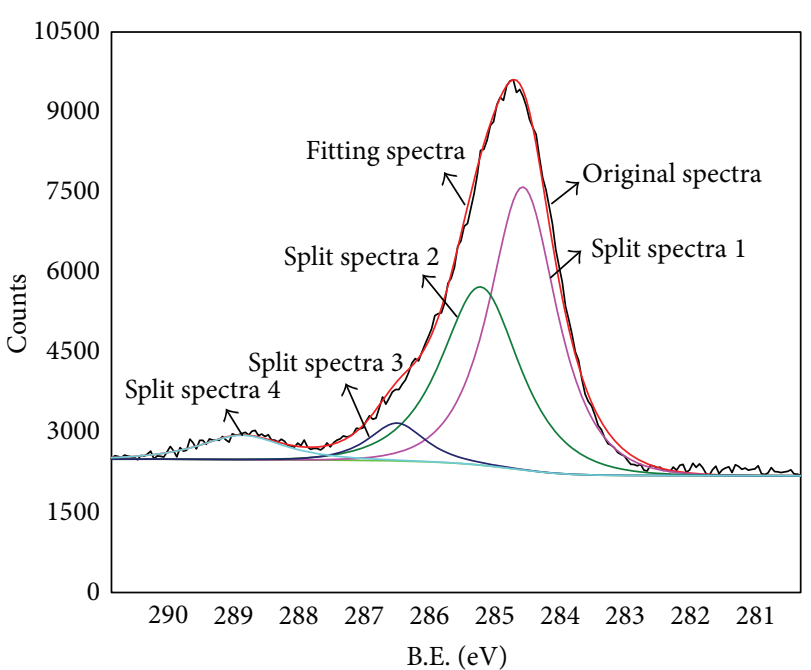

Distilled water

(a)

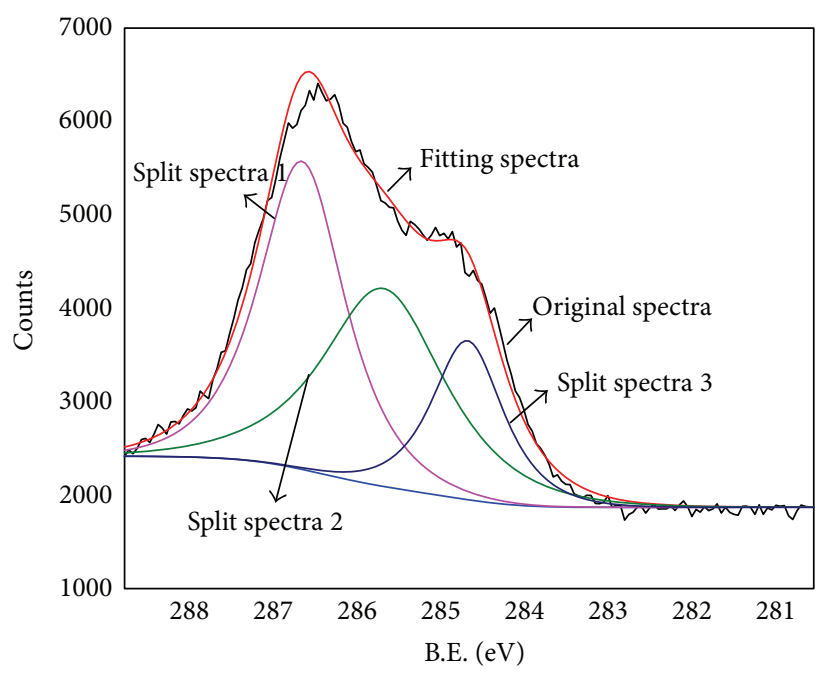

- $0.10 \%$ FW- 134

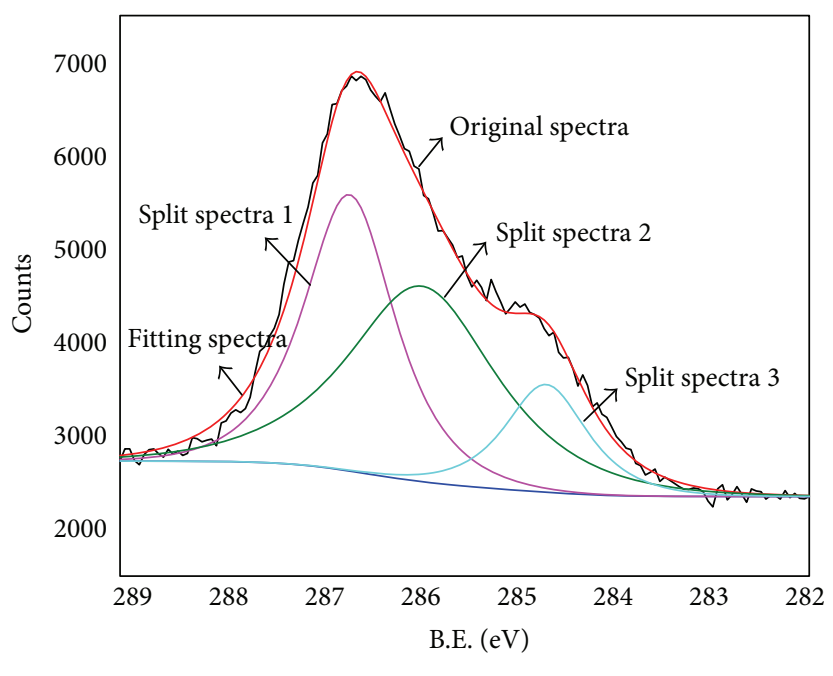

0.05\% FW-134

(b)

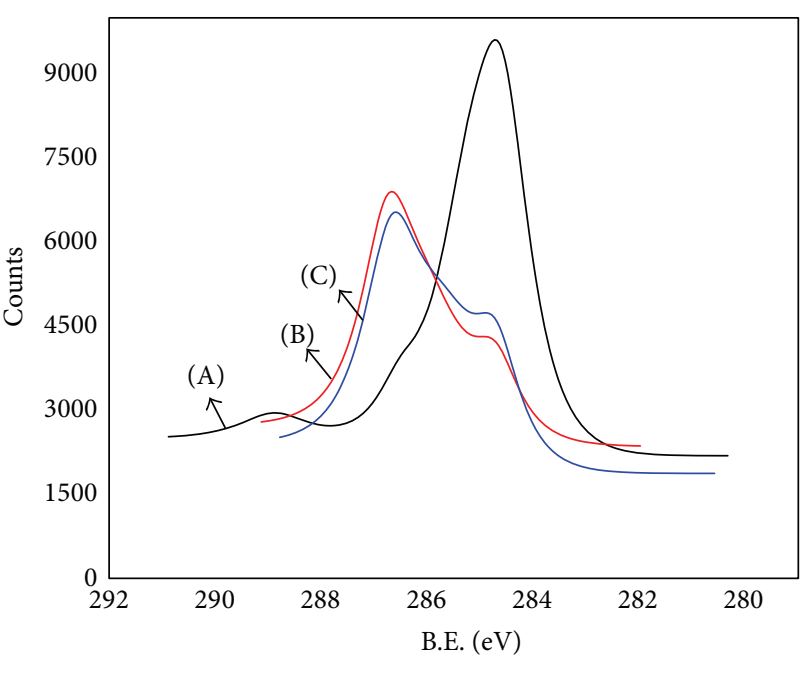

(A) Distilled water

(B) $0.05 \% \mathrm{FW}-134$

(d)

FIGURE 5: XPS C1s spectra of samples adsorbing FW-134 and contrast diagram.

$0.2 \%$ are $71.9^{\circ}, 101.2^{\circ}$, and $92.3^{\circ}$, respectively, which mean a good hydrophobic performance and interfacial modification ability of FW-134. After the mica surface is being cleaned with distilled water for 48 hours, there is still a lot of surfactant FW-134 adsorption on the mica surface (Figure 7). We conducted comparative experiments to verify whether the AFM data are reproducible. The adsorption area differences of FW-134 in $10 \mu \mathrm{m} \times 10 \mu \mathrm{m}$ on mica surface in comparative experiments are less than $\pm 6 \%$, which verified that AFM data reproducibility was good. As seen in Figure 7, compared with Figure 6, a part of FW-134 molecules adsorbed on the mica surface are cleared away and the adsorption thickness is reduced, but the adsorbed layer still shows a uniform distribution, which indicts that $0.1 \% \mathrm{FW}-134$ has reached a saturated adsorption state on the surface of mica.

\section{Discussions}

Under the conditions of water oscillations, FW-134 on the mica surface is mainly physical adsorption, generally including the electrostatic and dispersion force adsorption. Because of characteristics of $\mathrm{F}$ atoms in fluorine surfactant molecules (the most electronegative and the minimum atomic polarizability) and the carbon chain of "shielding," the C-F bond is not easy to be polarized, and dispersion forces of fluorine surfactant molecules are small. FW-134 adsorption on the mica surface force is electrostatic adsorption.

With an increase of concentration, FW-134 reaches a saturated adsorption state on the surface of mica. Because of "hydrophobic effect" [9] of FW-134 molecules, micelle may form on the mica surface, but the low dispersion force of 

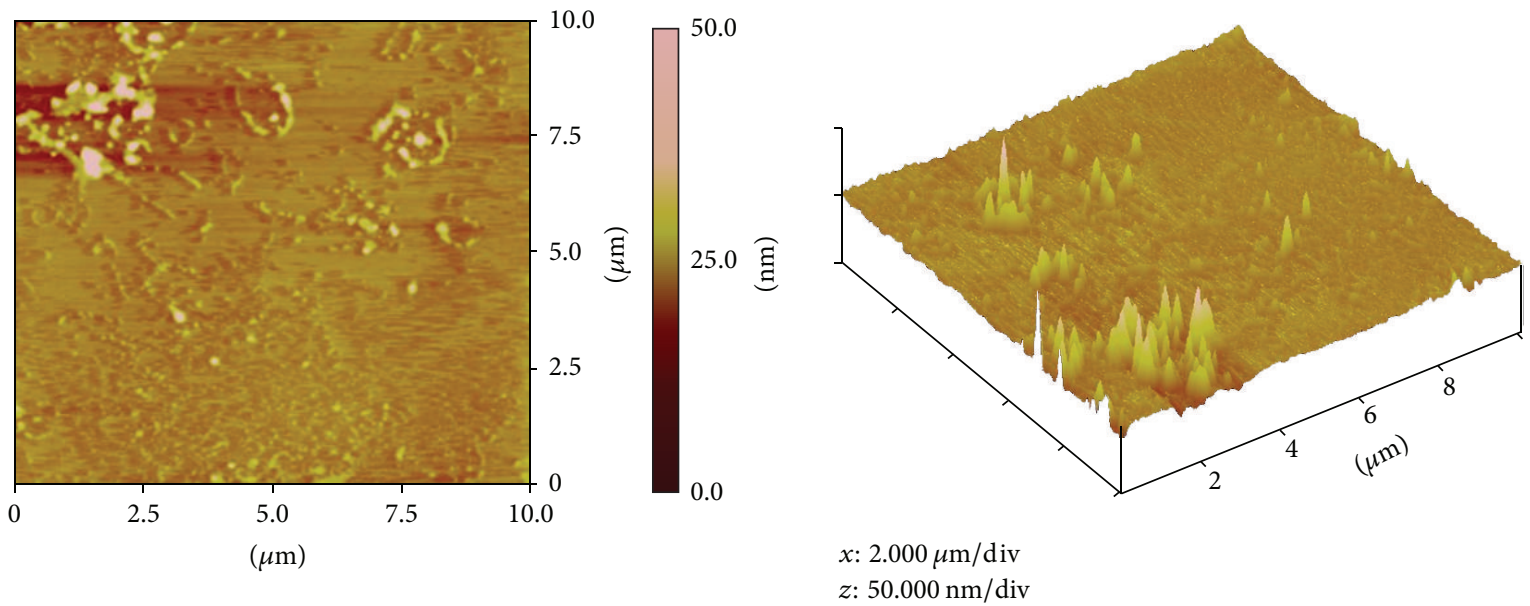

FIGURE 6: AFM plane height map and the three-dimensional topography (before cleaning).
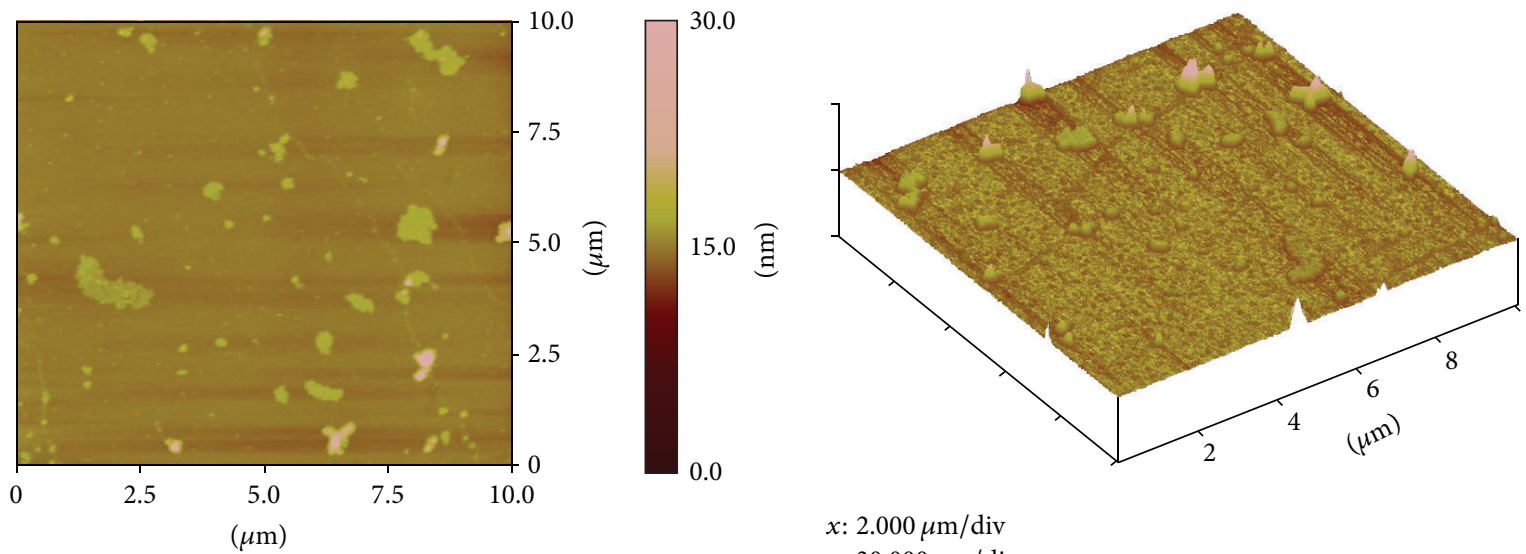

$x: 2.000 \mu \mathrm{m} / \mathrm{div}$

$z: 30.000 \mathrm{~nm} / \mathrm{div}$

FIGURE 7: AFM plane height map and the three-dimensional topography (after cleaning).

fluorine surfactant molecules and the thermodynamics effect under high temperature longtime oscillation lead to greatly weaken surface micelle formation and multilayer adsorption, so FW-134 adsorption on the mica surface has a single layer structure under the oscillation at $90^{\circ} \mathrm{C}$ when it reaches the saturated adsorption (Figure 8).

Owing to an outstanding high surface activity of fluorine surfactant, its $0.05 \% \sim 0.1 \%$ solution concentrations can decrease the surface tension of the aqueous solution to below $20 \mathrm{mN} / \mathrm{m}$. Low surface energy of fluorine or a silicon treatment agent is widely used in the surface modification to enhance the surface hydrophobicity. Genzer and Efimenko [21] and Peng et al. [23] used the fluorine surfactant treatment agent on the material surface fluorination modification treatment and successfully obtained a super hydrophobic surface.

By electrostatic adsorption on the mica surface, a cationic hydrophilic ionic bond of FW-134 molecules is inward and its fluorocarbon hydrophobic chain is outward. The maximum C-F peak and the highest percentage of the area (Figure 5 and Table 3 ) show that the micro- and nanostructure like a "lotus effect" is formed on a solid surface, so the wettability alteration effect is good due to low surface energy and the hydrophobic surface. Thus $0.05 \% \sim 0.1 \% \mathrm{FW}-134$ solution can also have low surface tension and a good wettability reversal effect. Because of fluorinated surfactant being expensive, the compound and synergistic reaction of fluorine surfactant and common surfactant considering the cost and the effect might be worth developing, but it should be emphasized that counterions have great influence on the fluorine surfactant properties and adsorption behavior.

\section{Conclusions}

Fluorine surfactant adsorption on mica surfaces under the condition of oscillation at $90^{\circ} \mathrm{C}$ causes a hydrophilic surface to become hydrophobic structure with the strong ability of modifying interface and reversing wettability.

Fluorine surfactant adsorption on the mica surface is mainly physical adsorption and has a single layer structure when it reaches the saturated adsorption, which may be the reason that the period of interface modification validity is short. 


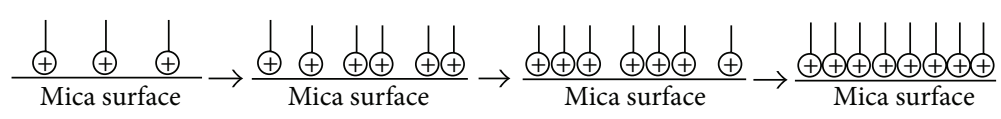

FIGURE 8: FW-134 adsorption schematic diagram on mica surface.

$0.05 \% \sim 0.1 \% \mathrm{FW}-134$ can decrease the surface tension of the aqueous solution to below $20 \mathrm{mN} / \mathrm{m}$ and show high quality of wettability alteration effect.

\section{Conflict of Interests}

There is not any conflict of interests regarding the publication of this paper.

\section{Acknowledgments}

The authors gratefully acknowledge financial support from The National Basic Research Program (973) of China (no. 2010CB226705), China Scholarship Council fund, and The National Municipal Science and Technology Project (2011ZX05018).

\section{References}

[1] L. You, Y. Y. Kang, Y. Chen et al., "Stress sensitivity of fractured tight gas sands in consideration of fractures and water saturation," Journal of China University of Petroleum (Edition of Natural Science), vol. 30, no. 2, pp. 59-63, 2006.

[2] D. B. Bennion, R. F. Bietz, F. B. Thomas, and M. P. Cimolat, "Reductions in the productivity of oil and low permeability gas reservoirs due to aqueous phase trapping," Journal of Canadian Petroleum Technology, vol. 33, no. 9, pp. 45-54, 1994.

[3] D. B. Bennion, F. B. Thomas, R. F. Bietz, and D. W. Bennion, "Water and hydrocarbon phase trapping in porous mediadiagnosis, prevention and treatment," Journal of Canadian Petroleum Technology, vol. 35, no. 10, pp. 29-36, 1996.

[4] L. You and Y. Kang, "Integrated evaluation of water phase trapping damage potential in tight gas reservoirs," in Proceedings of the 8th European Formation Damage Conference, Scheveningen, The Netherlands, May 2009.

[5] T. Yoshimura, A. Ohno, and K. Esumi, "Equilibrium and dynamic surface tension properties of partially fluorinated quaternary ammonium salt gemini surfactants," Langmuir, vol. 22, no. 10, pp. 4643-4648, 2006.

[6] K. Li and A. Firoozabadi, "Experimental study of wettability alteration to preferential gas-wetting in porous media and its effects," SPE Reservoir Evaluation \& Engineering, vol. 3, no. 2, pp. 139-149, 2000.

[7] G.-Q. Tang and A. Firoozabadi, "Relative permeability modification in gas/liquid systems through wettability alteration to intermediate gas wetting," SPE Reservoir Evaluation \& Engineering, vol. 5, no. 6, pp. 427-436, 2002.

[8] G.-Q. Tang and A. Firoozabadi, "Wettability alteration to intermediate gas-wetting in porous media at elevated temperatures," Transport in Porous Media, vol. 52, no. 2, pp. 185-211, 2003.

[9] B. Adibhatla, K. K. Mohanty, P. Berger, and C. Lee, "Effect of surfactants on wettability of near-wellbore regions of gas reservoirs," Journal of Petroleum Science and Engineering, vol. 52, no. 1-4, pp. 227-236, 2006.
[10] M. Fahes and A. Firoozabadi, "Wettability alteration to intermediate gas-wetting in gas-condensate reservoirs at high temperatures," SPE Journal, vol. 12, no. 4, pp. 397-407, 2007.

[11] A. Delavarmoghaddam, S. A. Mirhaj, and P. L. Zitha, "Gas condensate productivity improvement by chemical wettability alteration," in Proceedings of the 8th European Formation Damage Conference, Scheveningen, The Netherlands, 2009.

[12] X.-F. Liu, Y.-L. Kang, L.-J. You, and P. Wu, "Experimental study on amphiphobic surface treating to prevent reservoir from aqueous phase trapping damage," Natural Gas Geoscience, vol. 20, no. 2, pp. 292-296, 2009.

[13] K. Li, Y. Liu, H. Zheng, G. Huang, and G. Li, "Enhanced gascondensate production by wettability alteration to gas wetness," Journal of Petroleum Science and Engineering, vol. 78, no. 2, pp. 505-509, 2011.

[14] S. Wu and A. Firoozabadi, "Simultaneous increase in gas and liquid relative permeabilities and reduction of high-velocity coefficient from wettability alteration," Journal of Canadian Petroleum Technology, vol. 50, no. 2, pp. 17-23, 2011.

[15] Y. Li, G. Jiang, L. Li et al., "The effect of a novel gas-wetting reversal FC-1 on the condensate gas reservoir core," Petroleum Science and Technology, vol. 32, no. 1, pp. 1-7, 2014.

[16] H. Milsch, G. Blöcher, and S. Engelmann, "The relationship between hydraulic and electrical transport properties in sandstones: an experimental evaluation of several scaling models," Earth and Planetary Science Letters, vol. 275, no. 3-4, pp. 355363, 2008.

[17] S. Wu and A. Firoozabadi, "Effect of salinity on wettability alteration to intermediate gas-wetting," SPE Reservoir Evaluation \& Engineering, vol. 13, no. 2, pp. 228-245, 2010.

[18] S. Wu and A. Firoozabadi, "Permanent alteration of porous media wettability from liquid-wetting to intermediate gaswetting," Transport in Porous Media, vol. 85, no. 1, pp. 189-213, 2010.

[19] O. Seiedi, M. Rahbar, M. Nabipour, M. A. Emadi, M. H. Ghatee, and S. Ayatollahi, "Atomic force microscopy (AFM) investigation on the surfactant wettability alteration mechanism of aged mica mineral surfaces," Energy and Fuels, vol. 25, no. 1, pp. 183-188, 2011.

[20] A. Niecikowska, J. Zawala, and K. Malysa, "Influence of adsorption of n-alkyltrimethylammonium bromides (C8, C12, C16) and bubble motion on kinetics of bubble attachment to mica surface," Physicochemical Problems of Mineral Processing, vol. 47, pp. 237-248, 2011.

[21] J. Genzer and K. Efimenko, "Creating long-lived superhydrophobic polymer surfaces through mechanically assembled monolayers," Science, vol. 290, no. 5499, pp. 2130-2133, 2000.

[22] K. Cinku and B. Baysal, "Investigation of adsorption behavior of phosphonium salts onto Na-montmorillonite," Physicochemical Problems of Mineral Processing, vol. 50, no. 2, pp. 417-432, 2014.

[23] M. Peng, H. Li, L. Wu, Q. Zheng, Y. Chen, and W. Gu, "Porous poly(vinylidene fluoride) membrane with highly hydrophobic surface," Journal of Applied Polymer Science, vol. 98, no. 3, pp. 1358-1363, 2005. 

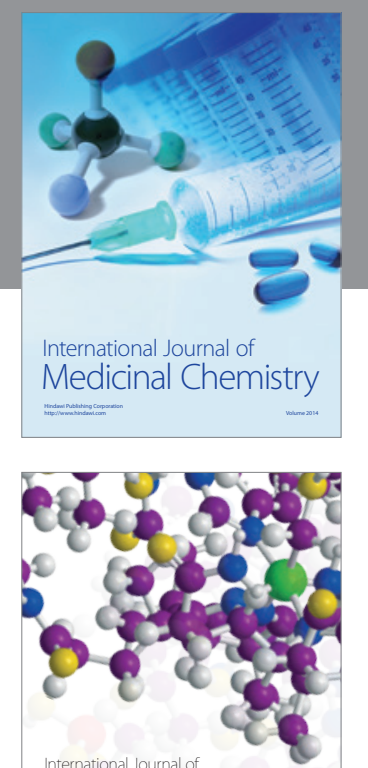

\section{Carbohydrate} Chemistry

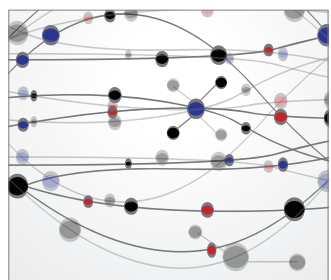

The Scientific World Journal
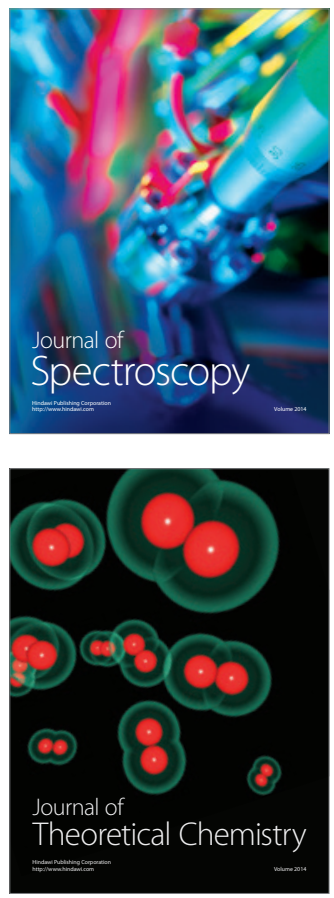
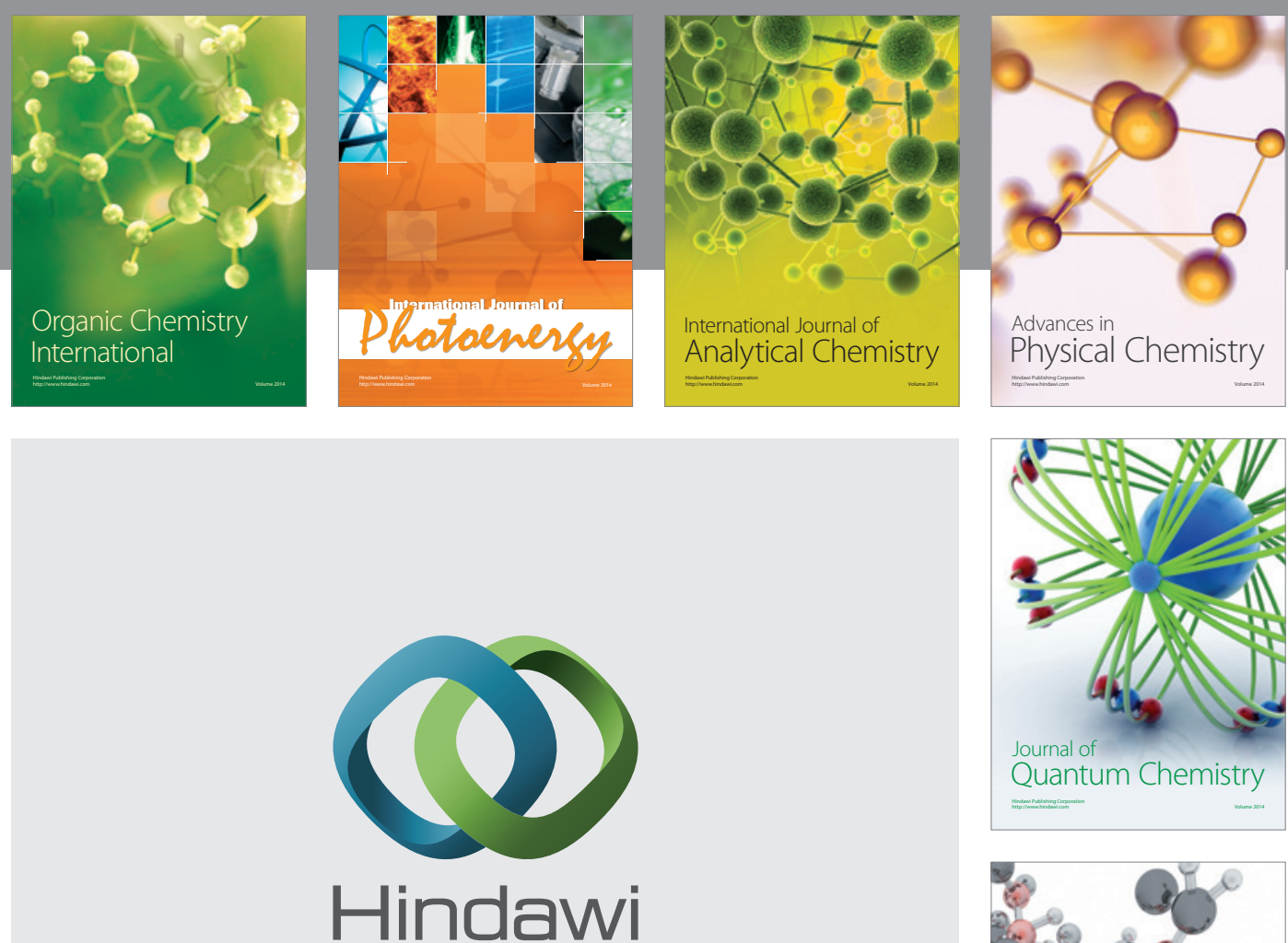

Submit your manuscripts at

http://www.hindawi.com

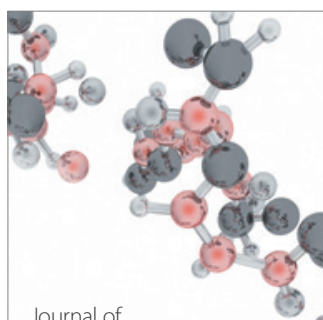

Analytical Methods

in Chemistry

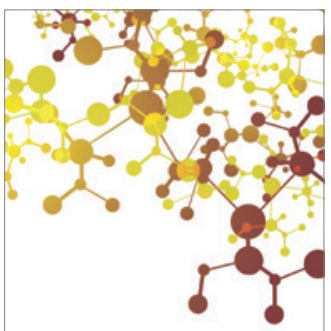

Journal of

Applied Chemistry

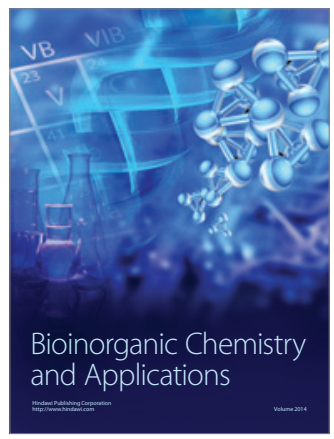

Inorganic Chemistry
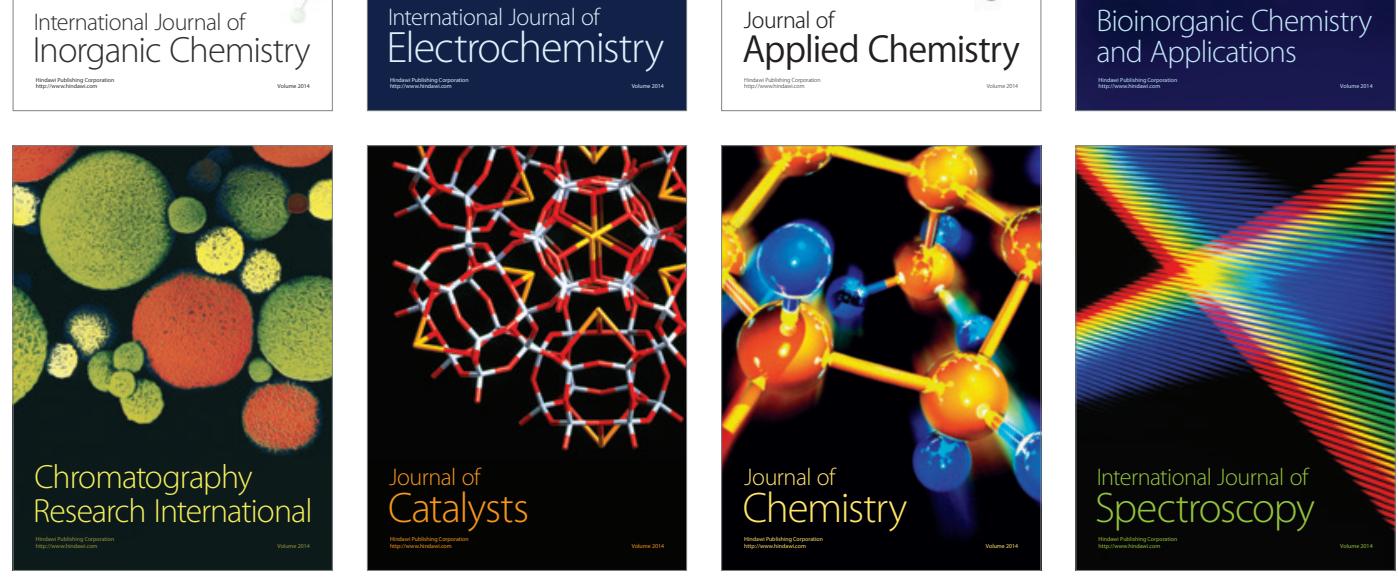